\title{
THE CHINA-PAKISTAN ECONOMIC CORRIDOR (CPEC) IS A GATEWAY TO PEACE, STABILITY, AND TOURISM SUSTAINABILITY
}

\author{
Mohammad Alam \\ Lecturer, Department of Tourism and Hospitality, Hazara University Mansehra \\ alampices@gmail.com \\ Danish Ali \\ Lecturer; Department of Tourism \& Hotel Management, University of Swabi Pakistan \\ danishalikhan763@gmail.com \\ Muhammad Haris Ali Jadoon \\ Lecturer, Department of Tourism and Hospitality, Hazara University Mansehra \\ m.harisalijadoon@gmail.com
}

\begin{abstract}
Tourism development and flow are directly influenced by the travel and transportation linkages. Transit routes are a vivacious segment of the world trade, places connectivity, tourism, and travellers comfortability, reducing price and time between destinations. The 1,878-kilometer route from Khunjrab Pass will connect the Brahma Bahtar Interchange on the M1 Motorway with the city of Gwadar on the Western Alignment. The new trade and business dimensions are arising from the CPEC transit route between Pakistan and China. Gwadar Port has the potential to undertake a critical position in Pakistan's economic resurgence. This study is established on the qualitative method based on the case studies technique as secondary data analysis. CPEC would offer several direct and indirect benefits to the country, people and especially the local community by securing employment, growing wages, and establishing SMTEs. The CPEC's economic growth and incentives will enable the provinces into the process of national change. Tourism increases awareness, understanding, poverty reduction, promote development, increase jobs, peace.
\end{abstract}

Keywords: CPEC, Pakistan, China, Tourism, Gawadar, Connectivity, Transit route

\section{INTRODUCTION}

Musharraf's a trade and energy initiative was formally introduced in 1995 (Ajmal, 2019). CPEC was formally announced in 2003 following a meeting in Beijing between President Hu Jintao and Chief Pervez Musharraf (Ramay, 2016). In 1950s diplomatic relationships straddled China and Pakistan into this new era of partnership in many fields, including trades (Kayani et al., 2013). The trade bond into this land existed for millennia during Han Dynasty (Alam, 2020). World Bank analysis shows that Pakistan- China business is worth around 13.2 billion dollars in 2017-18 and has the potential for growth (Ajmal, 2019). The Indian Ocean is a $73 \mathrm{mn} \mathrm{km}^{2}$ waterbody that incorporates the Gulf of Persia, Red Sea, Andaman Sea, and the Strait of Malacca, 38 coastal states and 13 landlocked countries that depend on the Indian Ocean sea transport (Gill, 2019). The coastline of Pakistan can be divided into five segments; Gwadar, Lasbella in Baluchistan and Karachi, Thatta, Rann in Sindh. Gwadar Port is Pakistan's third-largest deep-water harbour, situated at the crossing point of sea transportation and oil trading routes and linking three continents: South Asia, West Asia, and Central Asia (Conrad, 2017). The CPEC is under OBOR initiatives of China to Gawadar seaport in Pakistan by adding an extensive network of rail \& highways, airports, and pipelines (Riaz and Mi 2017). CPEC investments are spread over 15 years; it will translate to poverty alleviation and economic stability (Khalil 2017; (Ajmal, 2019). CPEC is a geopolitical pathway framework that will impact the Pakistan economy; locals' living standards have been studied (A. Khan, Bibi, Lyu, Alam, et al., 2020; A. Khan, Bibi, Lyu, Garavelli, et al., 2020). This modification will ensure regional development, economic stability, and peace (A. Khan, Bibi, Ardito, et al., 2020; A. Khan, Bibi, Lorenzo, Lyu, \& Babar, 2020). This transit route starting Kashgar (China) enter into the Khunjrab pass (Pakistan Gilgit Baltistan,) 
reach to Gwadar port in the Arabian sea (Baluchistan, Pakistan) close to the Strait of Hormuz (Riaz and M, 2017). The 1,878-kilometer route from Khunjrab Pass will connect the Brahma Bahtar Interchange on the M1 Motorway with the city of Gwadar on the Western Alignment. Tourist traffic increased by approximately $24.4 \%$ in 2017 , with $90 \%$ of tourists opting to travel by car; only $8.5 \%$ and 1.8 percent opted to travel by rail and air, respectively.

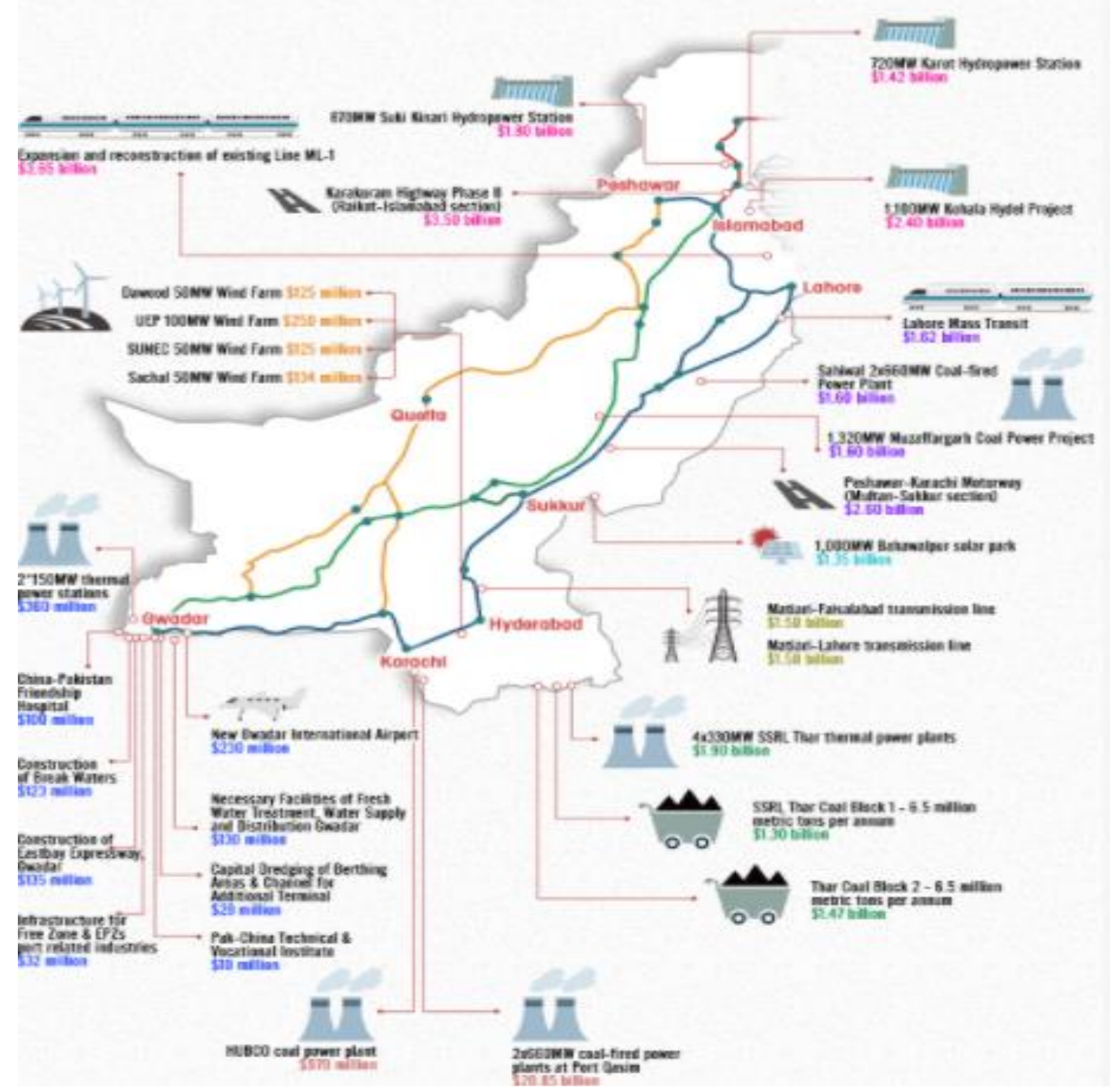

Figure 1: Major projects along the China-Pakistan Economic Corridor(CPEC)

(Source: Major projects along the China-Pakistan Economic Corridor(CPEC) - Global Times)

Pakistan's tourism revenue was $\$ 19.4$ billion in 2017, and it is projected to grow to $\$ 36.1$ billion by 2030, a 24.4 percent growth over the previous two years (Manzoor, 2019). The World Travel \& Tourism Council (WTTC) reported a share of the tourism industry 5.9\% to Pakistan's GDP, producing 3.9 million employment in 2019. The expert evaluated, if Pakistan's tourist industry expands to 11 percent GDP, resulting in 6.27 million employment in the tourism industry (Daily Pakistan, 2021). In contrast, 39,000 Chinese came to Pakistan in the past five years (Gishkori, 2018). In the northern areas, 250 thousand travellers travelled to Pakistan. Business travel spending is predicted to jump from $\$ 1.9$ bn in 2016 to $\$ 3.3$ bn in 2026 (The Tribune, 2017). The projects in the CPEC will induce opportunities directly and indirectly; the local community will get jobs to enhance their income or start SMTEs, the fishermen will have a chance to sell their products in the global market (Idrees, 2015). Furthermore, the developments in Gwadar Port will enable the local community who can startups tourism entrepreneurship .i.e. rest houses, restaurants, shops, workshops, transports, tour guides, tour operators or selling and hiring equipment of watersports which can enhance their household revenue. 


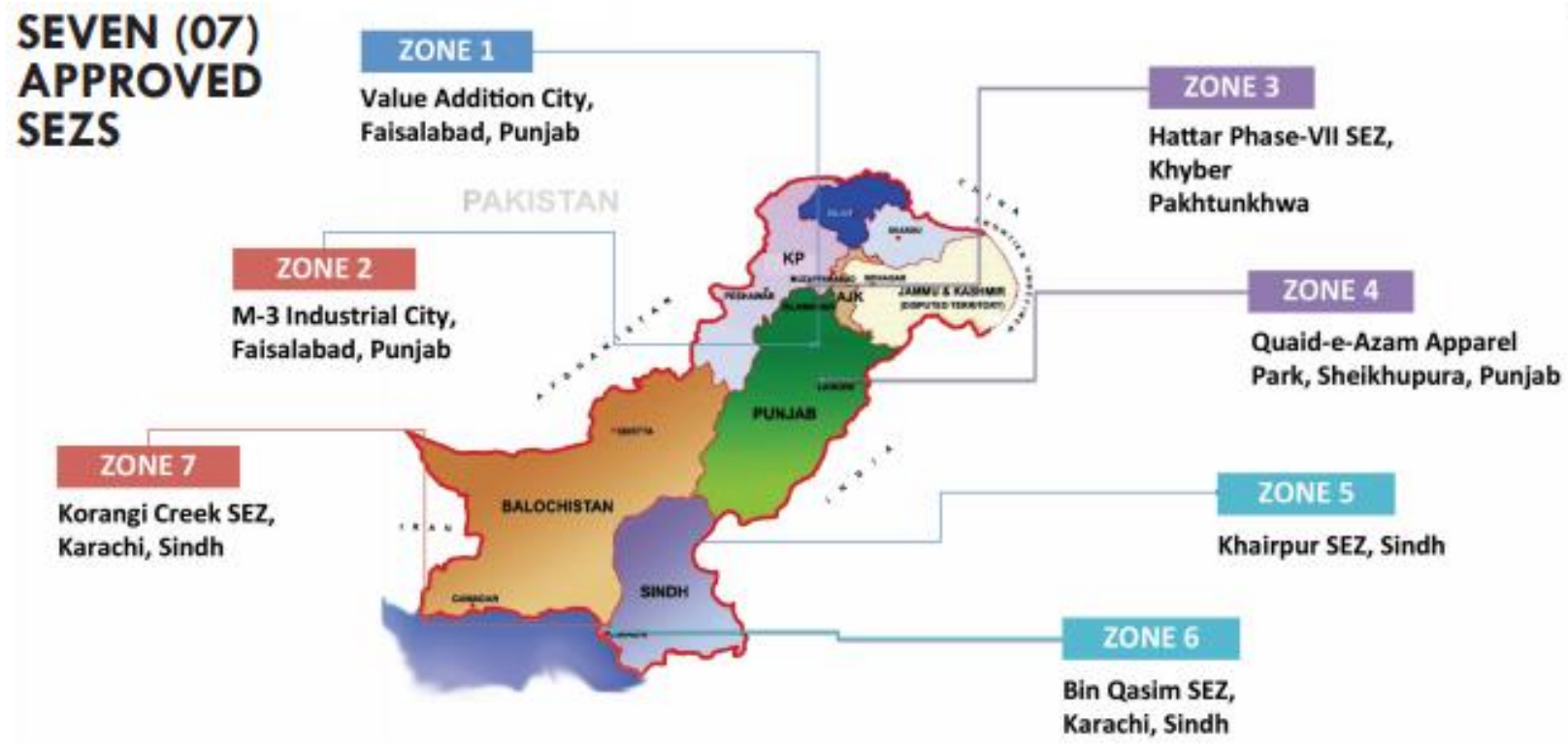

Figure 2: Special Economic Zones

(Source: Diplomate 2020; Pakistan Report)

\section{METHODOLOGY}

This study examines the tourism niche development of CPEC projects. This article refers to the case study method, which is currently used in many studies as a learning activity where the individual is confronted with a specific issue (Bennett, 2004). The case study method is reliant, but it is complementary to the structured and empirical approach (Feagin, Orum, \& Sjoberg, 1991). The case study methodology is the most frequently used tool for researchers involved in qualitative studies in academia (Baskarada, 2014). The examination of one or many "cases sets," which may be regarded as examples, samples, or contexts in which the issue or phenomena can be explored, is part of case study technique. The researcher is in charge of determining the case's conditions, or what is accepted omitted. In a case study, an actual trend is discussed in its basic sense, considering that the context influences (Kaplan \& Maxwell, 2005). The secondary evaluation of available data is a technique, offers broad recommendations for undertaking secondary assessment of current facts (Cheng, H. G., \& Phillips, M. R, 2014). Therefore, a qualitative research method is utilised in this case analysis. This study lies on a secondary source of study reviewed from various articles journals, newspapers, and policy papers. The focus of the paper is reshaping travel and tourism through CPEC development.

Tourism through CPEC opportunities in Pakistan was assessed and analysed as follows:

- Tourism's perceived value in terms of tourism accessibility will make a significant difference.

- The economic and cultural exchanges will build a response and a comparative development potential for growth in the region.

Traditionally, China was known as a sleeping giant. However, China is already assuming a critical role not just from the Asian countries but also in the whole world (Abid \& Ashfaq, 2015). Nazneen, $\mathrm{Xu}$, and Din (2019) empirically measure interrelationships between the potential effects of transportation improvements of the China-Pakistan Economic Corridor (CPEC) and encouragement for tourism and regional development. CPEC is a coextensive and ambitious project for both nations. Its tangible benefit is reducing time, transportation cost, investment opportunities, industrial development, and promoting tourism (S. A. Ali, Haider, Ali, Ali, \& Ming, 2017). The investment opportunities will boost tourism infrastructure, products, services quality and with positive publicity, the places where people will want to visit (Hameed, Ali, \& Khan, 2020). Pak- China tourism is seeing significant growth due to effective visa policies, robust vacation travel, and the activity of more foreign tourism, and more foreign flights (S. A. Ali et al., 2017). The CPEC would enhance the tourism industry's quality of services and benefit both the two nations to robust socio-cultural and economic development. Northern Pakistan is well-known for its natural serenity for its rich culture and history (A. Khan, Bibi, Lyu, Alam, et al., 2020). It can also attract many tourists to generate 
tourism revenue (A. Khan, Bibi, Ardito, et al., 2020). The CPEC would bring a new era of tourism development in Pakistan by improving standards of industrial components and making careers for great numbers of people. Besides, it will expand the KKH and flourish different SMEs and cultural activities. Gawadar is a splashing point and plays a pivotal role in the politics of Asia.

\section{DISCUSSION}

\section{Improving Infrastructure and Accessibility}

Pakistan's infrastructure is expanding as a part of CPEC, making it easier for travellers to visit the country's major tourist destinations, trade zones, terminals and terminus. Travel business is directly connected with the development of travel infrastructure will instantly enhance accessibility (A. Khan, Bibi, Lyu, Latif, \& Lorenzo, 2020; A. Khan, Bibi, Lyu, Raza, et al., 2020). Cooper (2000) identified that a tourist destination consists of various elements identified as 4 As, Attraction, Access, Amenity and ancillary services (UK essays, 2018). Hameed et al. (2020) suggest that Scenic beauty, accessibility, weather and security are the main influential factors of visitors preference. The routes under CPEC will increase comfort, reduce the time between the destinations. CPEC decreases transit time for freight and people (Rehman, Hakim, Khan, \& Khan, 2018). The CPEC is a balance of debt and investment; it is focusing on $17.7 \%$. i.e., US\$17 will be spent on the transportation and logistics services in Pakistan (http://www.aei.org). It'll enhance trade and increase employment, tourism, and growth in rural areas and link rural areas to urban components. Two mega infrastructures, i.e., Sukkur to Multan section and KKH Phase II from Havellian to Thakot section, is some of the most significant transportation infrastructure developments, using about ten thousand local workforces. The CPEC transit route will also add a demand for eight hundred thousand automobiles over the next fifteen years and trigger secondary and tertiary employment (Alam, 2020).

\section{Table No.1 Relative Distance Chart}

\section{Place of Origin $\quad$ Distance in $\mathrm{Km}$}

\begin{tabular}{r|l} 
Karachi & $(627.1 \mathrm{~km})$ via Makran Coastal Hway/N-10 \\
Pasni & $(126.0 \mathrm{~km})$ via Makran Coastal Hwy/N-10 \\
Quetta & $(914.8 \mathrm{~km})$ via N-85 \\
Lahore & $(1,860.6 \mathrm{~km})$ via Makran Coastal Hway/N-10 \\
Islamabad & $(2,060.4 \mathrm{~km})$ via Makran Coastal Hway/N-10 \\
Hasanabdal & $(2,080.3 \mathrm{~km})$ via Makran Coastal Hway/N-10 \\
Peshawar & $(2,199.8 \mathrm{~km})$ via Makran Coastal Hway/N-10 \\
Chitral & $(2,406.4 \mathrm{~km})$ via Makran Coastal Hway/N-10 \\
Skardu & $(2,656.3 \mathrm{~km})$ via Makran Coastal Hway/N-10 \\
Gilgit & $(2,534.0 \mathrm{~km})$ via Makran Coastal Hway/N-10 \\
Sost & $(2482.0 \mathrm{Km})$ via N-50 \\
Kunjrab Pass & $(2788 \mathrm{Km})$ via Makran Coastal Hway/N-10
\end{tabular}

Source: Relative distance calculated from online google distance.

\section{Peace Initiative}

(www.maps.google.com)

The China-Pakistan Economic Corridor (CPEC) is critical for Pak-China security; critics have referred to it as a "peace corridor" (Rahman \& Zailani, 2017). It is believed that security and economic growth are inextricably linked, and that progress in one will supplement progress (Ehrlich \& Lui, 1991). CPEC will give Pakistan's regional problems historical insinuations, i.e., wars, terrorism, instability, and its responses. China has provided regional connectivity to encourage peaceful coexistence (Khattak \& Khalid, 2013). 
The expansion of CPEC would also assist in promoting shared trust, and people-to-people communications will enhance public diplomacy. These initiatives would also deepen the two countries' very strong bonds of friendship. Chaziza (2016) investigated that China-Pakistan ties could have far from geo-economic and geostrategic repercussions, not just for the Arab world and the larger Asia area, which both the US and China vie for dominance. By extending the regional connectivity will bring peace and prosperity to the neighbouring countries. The best strategy is to promote economic, social, and cultural relations with neighbouring countries, facilitating the resolution of these challenges in a non-military manner while also promoting regional stability (Fatima., 2019). Pakistan followed a non-alignment strategy in the very first half. However, circumstances forced Pakistan into the US bloc, yet Pakistan's foreign policy faced several obstacles until the Global War on Terror (GWOT) following 9/11. The 50 years of Sino-Pk friendship ultimately bring Pakistan into trade allies through CPEC. Keeping in mind the implications of Pakistan's past regional problems, China has provided the opportunity on regional connectivity to encourage peace, harmony and economic development.

\section{Economic Stability}

Pakistan-China bilateral trading is positive and growing faster, while Pakistan's international trade can expand in the east-west. Haq and Farooq (2016) forecasted a positive impact on the social sector and living standards in various districts. Pakistan Infrastructure growth will improve economic output, raise manufacturing capacity, reduce transactional and trade prices, and absorb the unemployed (Pravakar Sahoo 2010). Furthermore, as a result of this flow, Pakistan's Small and Medium Enterprises (SME) sector will prosper, enabling joint ventures. CPEC would attract foreign direct investment, fight war phobia, bring peace, and contribute to stability, growth, and economic development (Abid \& Ashfaq, 2015). Gwadar Port has the potential to undertake a critical position in Pakistan's economic resurgence (S. A. Khan, 2013). Gwadar gives two connections, in the East and west, as well as the north and south (S. A. Khan, 2013). Developing infrastructure draws visitors to less well-known places, turning them into vibrant destinations (Khadaroo \& Seetanah, 2007). Gwadar will serve as a trading gateway for China, Afghanistan, Central Asia, and the Gulf, then use the port as a safe route for oil imports, but it could also be used as a naval base to expand its presence in the Indian Ocean (Malik 2012). Since its aim of extending the manufacturing capability for exportoriented manufacturing, 16 SEZs (special economic zones) have been structed, nine of which are part of CPEC. Venture capitalists from all other nations are welcome in SEZs. Automobile, engineering, technology, Halal food, textiles, plastics, agriculture products, food processing, pharmaceuticals, chemicals, and allied industries are among the sectors that are likely to be developed in SEZs.

According to data presented by the Indian Council of World affairs, CPEC expects to expand 17,000 MW of energy with an investment of 34 billion dollars. In addition, about 4 billion dollars are being rendered on high-speed highways, motorway networks connecting Gwadar to China via the Khunjrab pass. The remaining amount from the initial $\$ 46$ billion projects will be used to build Gwadar Port/City, construct economic zones, and laid fibre optic cable (Bhattacharjee, 2015). The value of the CPEC task is now really worth $\$ 62$ billion. IMF estimated that CPEC will bring $\$ 3$ to $\$ 13$ billion in revenue to Pakistan's GDP by 2024 (Chen, Joseph, \& Tariq, 2018). The competitiveness of a Gawadar port relies on its hinterland because the port serves as a transportation hub; therefore, transportation networks are evolving with international partners. Gwadar means "The Gate of the Air" in the native dialect. Pakistan's dream of making a deep water port at Gwadar is almost as old as its creation (Anwar, 2010). The Portuguese seized the coast of Makran (along with Gwadar) in the 16th century AD. In the 18th century, the Khan of Kalat granted Gwadar to the Sultan of Oman. After two centuries, it was sold back to Pakistan in 1958 (Zaheer, 2006). Gawadar's population expects to rise from 100,000 in 2017 to 2000,000 in the next 20 years(Deng, Yeo, \& Du, 2018). China and Pakistan are developing a strong economic partnership, which affects both countries and can expand and develop further. CPEC connects Pakistan with China and the central Asian states (Alam, 2020).

\section{Development}

Pakistan's coastline is approximately $990 \mathrm{~km}$ long, bifurcated in two parts, the Sindh Coast $(270 \mathrm{~km})$ and the Makran coast $(720 \mathrm{~km})$. Pakistan's Exclusive Economic Zone (EEZ) occupies an area of approximately 240,000 square Km. Pakistan's maritime region, including the continental shelf, stretches up to 350 nautical miles off the coast (Pakistan, 2016). The CPEC will start new opportunities for China and Pakistan, but for the whole regions, including the Middle East and Africa, 
by improving people-to-people contact and rising cultural co-operation (Ahmad, Mi, \& Fernald, 2020). CPEC will foster Pakistan and China's distinct traditions and cultures (L. Ali, Mi, Shah, Shah, $\& \mathrm{BiBi}, 2017)$. CPEC moves above the economic impact and has risen in thousands of Chinese already moved to create a social impact as many Chinese superstores, a traditional Chinese medicine hospital opens not only in Gwadar, and other major cities, but also in remote areas of Pakistan (Chen et al., 2018). Reuters estimated that more than 71,000 Chinese tourists visited the country last year on short-term visas, and 30,000 are migrated working in different projects (Aljazeea). The projects, including Gwadar Port, Central Railway Line, Karachi to Lahore Motorway, Gwadar-Rattu-Dero Motorway, Gwadar-Nawab Shah, LNG Terminal, Pipeline Project, Pak-China Friendship Hospital Gwadar, and borders Fiber Optic Data Communication (The nation, 2021). CPEC will improve investment advantages for Pakistani businessmen, which lead Pakistan towards the industrialisation and transformation of stunted sections and will develop a new labour market for both countries.

\section{Prosperity In Provinces}

It is said that Great Britain, at the height of its dominance, introduced colonies to the world; wars were introduced to the world by the United States and the Soviet Union. China will bring aspects of growth and peace to the world by following in foreign agenda driven by the "Principles of Peaceful Coexistence." (Khattak \& Khalid, 2013). The CPEC might impact the Balochistan region's economic insecurity, which was considered challenging (Gill, 2019). The CPEC is a multi-dollar Megaproject that further brings instability and development in overall Pakistan and the deprived in the provinces like Baluchistan, KP(Abid \& Ashfaq, 2015). The geographical accessibility of the various regions inside Pakistan and outside Pakistan will empower the community with business opportunities. In addition, the long-term plan (2017-2030) for economic regionalisation and globalisation, based on a tandem and co-operation campaign of the Federal, province, would improve collaboration and understanding in academia, socio-cultural interactions and regional knowledge, which will increase trade and commerce(Hilali, 2020). China is spending \$35 billion on the development of 19 power plants, $\$ 4.8$ billion on transforming Gwadar into South Asia's most busy shipping port by 2022, and Gawadar, Baluchistan, expected to emerge a world port city with over 500 thousand professionals in the city by 2023 (Orakzai, 2021).

\section{Tourism \& Tourism Initiative}

The long-term relationship between tourism revenue and economic development in Pakistan explained and confirmed that tourism revenue increased Pakistan's economic growth or vice versa (Adnan Hye, 2013). Investigation to tourism indicates that faster transportation will lead to a revisit of the destination (Nazneen et al., 2019). The Chines ventures create more opportunities for tourism development between the two countries; like the tour operators of both countries are seeking tours to the nearest areas. Tourism is seen as a catalyst for global peace (Pernecky, 2010). Soft power, demonstrated by tourism, gets more robust because of closely linked approaches to tourism; an appreciation of the destination, an appealing image, major events and tourists share the experience of the countries visited. In 2019, China reported that approximately 169.2 million outbound departures (statistica). Travellers were motivated to visit the best site, sightseeing, attractions, and experience different cultures. The Chinese tourist sees tourism as a renewed attitude to everyday life and knows this difference; they travelled abroad (Liang, 2016). Previous studies have indicated that visitors with a favourable view of the destination will participate in more trips inside the region (Schroeder, 1996). 


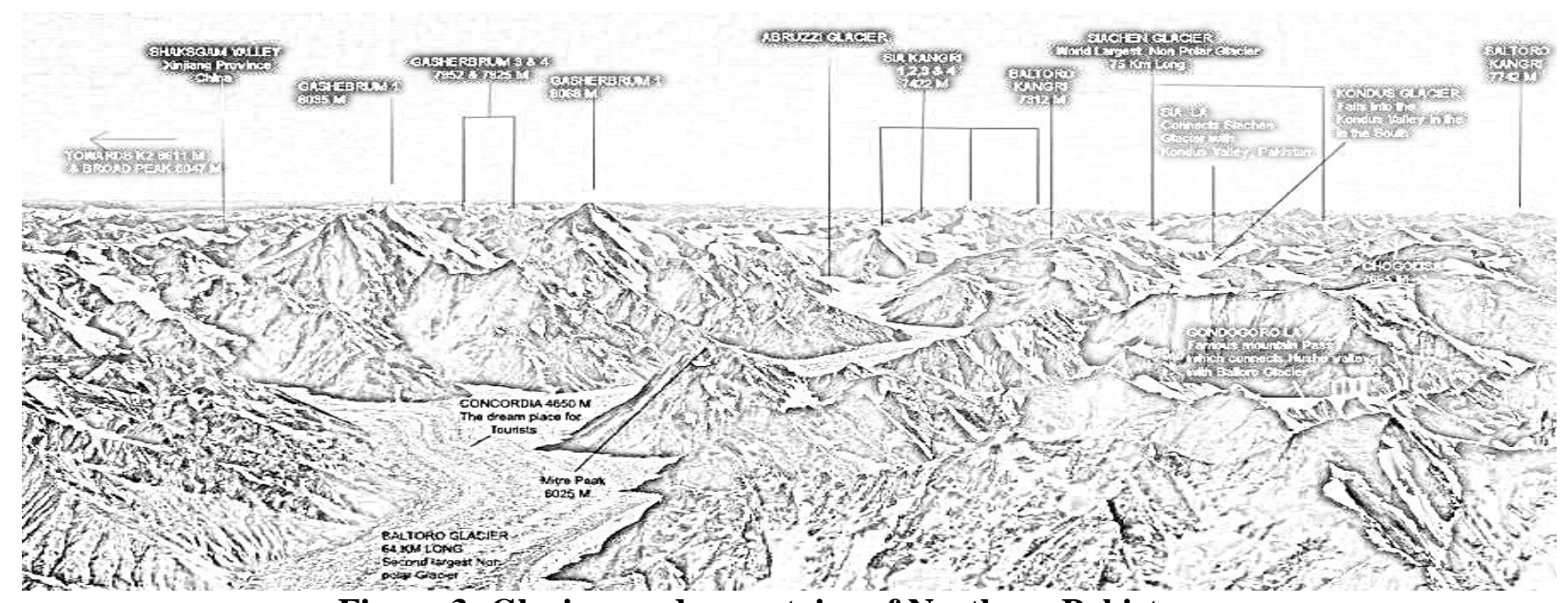

Figure 3: Glaciers and mountains of Northern Pakistan

Beach tourism is among the earliest types of tourism, also recognised as coastal tourism (Picken, 2017). The coastal strip with beautiful beaches and topographical features mark its alternative adventure zone in the south. Worldwide, it is anticipated that coastal tourism contributes to over 183 bn US\$, while data shows that Pakistan has an expected coastal tourism potential of about 45bn US\$ (Shaukat, 2020). The Arabian Sea coastline is a virgin beach stretched more than 700 kilometres long, accessible via Makran coastal highway and Kashgar-Gwadar road (S. A. Ali et al., 2017). The Tourism organisation, in collaboration with other stakeholders, access the coastal tourism development (Ullah, Khan, \& Haq, 2018). The Keti Bundar Karachi, Somiani Ormara, Gwadar, and Jiwani are the new popular hotspot coastal tourism potential zones. The development of beach resorts, other lodges, golf grounds, beaches, and soft adventure sports facilities will be the extension of coaster tourism adventures. The Telegraph report on Chinese tourists shows spending nearly $1000 \$$ during their business tour. Kabrio, (2019) explained that Chinese tourists who travelled overseas were 140 million last year, spending more than US $\$ 120$ billion and tourists are constantly searching for interesting places to visit in their neighbourhood. The Pakistani investors were encouraged to set up their trade firms in China to trade with Chines partners. The Pak China visa's policy was relaxed, extended, and improved. The actual tourist visitor's data is restricted, but the report confirms that it is increasing.

CPEC emphasises the effect education system in terms of training, student exchange, and human development, which brings up a spot for further interaction between the two countries(Tadesse, Muhua, \& Lei, 2020). Educational exchanges were developed as either an efficient approach of bridge exports or imports of culture, skills, particularly regarding improving mutual respect and acceptance(Eide, 1970).

\section{Implications}

The current research gives recommendations to CPEC authorities. This article will highlight the advantages of the CPEC-Tourism linkage for theoretical and practical implications. The present study promotes the tourism-related industry in the context of spatial tourism growth potential along CPEC and the realistic participation of the local community in the industry.

\section{Limitations}

The present study is based on secondary sources and preliminary information on the CPEC. The Tourism master plan or any other documents are scant from public reach, and even data on tourism is not published since 2009. The balance and imbalance of tourism concerning CPEC are required comprehensive analysis from the multidimensional analysis. Hence a survey is suggested for a complete examination of tourism resources, mapping, and linkage. The areas and zones to be identified for activity-based tourism to be developed on international standards.

\section{CONCLUSION}

CPEC is a blessing for Pak-China stronger relationship and will extend the cultural, political, strategic economic boundaries of greater prospects. The daggling economy, growing population, underdeveloped industrial standards, low skilled human resources are a few of the main issues of 
Pakistan. CPEC will ignite growth, development, peace through economic opportunities. The CPEC project provides several opportunities for tourism investment from Khanjrab to Gawadar. To boost tourism, both the local and international tourists should be provided with high-quality amenities and services. It is also essential to begin people-to-people exchanges for science, social, and educational interactions, to establish skills development concerning business proposed in CPEC projects, and to encourage best practices in the tourism industry. Various types of tourism can be promoted in Pakistan; Pakistan can learn from China's experiences in different travel and tourism industry segments. Pakistan's tourism strategies have mostly concentrated on traditional products by enticing international tourists in adventure and cultural tourism, however, the country has huge potential in the tourism sector. Online travel portals can tap the opportunity of Chinese visitor spending, and Pakistani tour companies are urged to establish an online presence. The universities should be involved to teach Chinese as a foreign language in the curriculum because the youth will be meeting Chine's visitors and businessmen. The government and link department must initiate awareness and capacity building training programs according to the demand of the CPEC potential market. The opportunity needs to be materialised into reality.

\section{REFERENCE}

Abid, M., \& Ashfaq, A. (2015). CPEC: Challenges and opportunities for Pakistan. Journal of Pakistan Vision, 16(2), 142-169.

Ahmad, R., Mi, H., \& Fernald, L. W. (2020). Revisiting the potential security threats linked with the China-Pakistan Economic Corridor (CPEC). Journal of the International Council for Small Business, 1(1), 64-80.

Ajmal, M. (2019). Pakistan and China through the lens of CPEC. https:// moderndiplomacy.eu/2019/02/09/pakistan-and-china-through-the-lens-of-cpec/

Alam, M., Ahmad, R., \& Nargiza, M. (2020). Pakistan - CPEC and Tourism Vinculum: A Corridor of Tourism Opportunities in Pakistan. Global sociological Review, V(III), 65-71. doi:https://doi.org/10.31703/gsr.2020(V-III).08

Alam, M. (2014). Decline \& Revival of lodging Industry in Sway valley; Economic review 2006-2012. [MPhil Dissertation Hazara University]. Mansehra.

Albu, C. E. (2016). Tourism and terrorism: A worldwide perspective. CES Working Papers, 8(1), 1.

Ali, L., Mi, J., Shah, M., Shah, S. J., \& BiBi, K. (2017). The potential socio-economic impact of china Pakistan economic corridor. Asian Development Policy Review, 5(4), 191-198.

Ali, S. A., Haider, J., Ali, M., Ali, S. I., \& Ming, X. (2017). Emerging Tourism between Pakistan and China: Tourism Opportunities via China-Pakistan Economic Corridor. International Business Research, 10(8), 204. doi:10.5539/ibr.v10n8p204

Anwar, Z. (2010). Gwadar deep sea port's emergence as regional trade and transportation hub: Prospects and Problems. Journal of Political studies, 17(2), 97.

Azhar, M., Khan, A. B., \& Shah, A. S. (2019). China Pakistan Economic Corridor: Opportunities and Considerations. FWU Journal of Social Sciences, 13(2).

Bibi, S., Khan, A., Qian, H., Garavelli, A. C., Natalicchio, A., \& Capolupo, P. (2020). Innovative Climate, a Determinant of Competitiveness and Business Performance in Chinese Law Firms: The Role of Firm Size and Age. Sustainability, 12(12), 4948.

Baskarada, S. (2014). Qualitative case study guidelines. Baškarada, S.. Qualitative case studies guidelines. The Qualitative Report, 19(40), 1-25.

Bennett, A. (2004). Case study methods: Design, use, and comparative advantages. Models, numbers, cases: Methods for studying international relations, 19-55.

Bhattacharjee, D. J. A. a. S. (2015). China Pakistan economic corridor.

Bibi, S., Khan, A., Qian, H., Garavelli, A. C., Natalicchio, A., \& Capolupo, P. (2020). Innovative Climate, a Determinant of Competitiveness and Business Performance in Chinese Law Firms: The Role of Firm Size and Age. Sustainability, 12(12), 4948.

Boniface, B., Cooper, C., \& Cooper, R. (2006). The future geography of travel and tourism. In Worldwide Destinations. Routledge.

Chaziza, M. (2016). China-Pakistan relationship: a game-changer for the Middle East? Contemporary review of the Middle East, 3(2), 147-161.

Chen, X., Joseph, S., \& Tariq, H. (2018). Betting big on CPEC. europeanfinancialreview.com, 61-69. 
Cheng, H. G., \& Phillips, M. R. (2014). Secondary analysis of existing data: opportunities and implementation. Shanghai archives of psychiatry, 26(6), 371.

Conrad, M. P. B. (2017). China's access to Gwadar Port: Strategic implications and options for India. Maritime Affairs: Journal of the National Maritime Foundation of India, 13(1), 5562.Deng, A., Yeo, A., \& Du, L. J. W. J. o. I. R. (2018). A Study on Gwadar Port International Competitiveness using Porter's Diamond Model. 4(1), 01-07.

Ehrlich, I., \& Lui, F. T. (1991). Intergenerational trade, longevity, and economic growth. Journal of political Economy, 99(5), 1029-1059.

Eide, I. (1970). Students as links between cultures: A cross cultural survey based on Unesco studies (Vol. 2): Oslo: Universitetsforlaget.

Farid, T., Iqbal, S., Khan, A., Ma, J., Khattak, A., \& Naseer Ud Din, M. (2020). The Impact of Authentic Leadership on Organizational Citizenship Behaviors: The Mediating Role of Affective-and Cognitive-Based Trust. Frontiers in Psychology, 11, 1975.

Fatima., A. (2019). A strategic shift in the foreign policy of Pakistan under CPEC. Asia,China Pakistan Economic Corridor,Pakistan,Pakistan's Foreign Policy. https:// theasiadialogue.com /2019/03/29/a-strategic-shift-in-the-foreign-policy-of-pakistan-under-cpec/

Feagin, J. R., Orum, A. M., \& Sjoberg, G. (1991). A case for the case study: UNC Press Books.

Fmprc.gov.cn (2003), "China-Pakistan joint declaration", available at: www. fmprc. gov. cn/ mfa_ eng/wjdt 665385/2649 665393/t40148.shtml.

Farr, G. M. (2017). Pakistan's Role in China's One Belt One Road Initiative. E-International Relations.

Gishkori, Z (2018). over 92-000 foreigners visit-pakistan-since-launch-of-cpec https:// www. thenews. com.pk.

Gill, D. M. (2019). The Geopolitics of the China-Pakistan Economic Corridor (CPEC) and its Security Implications for India. The Korean Journal of International Studies, 17(3), 337-353.

Hameed, H. B., Ali, Y., \& Khan, A. U. (2020). Regional Development through Tourism in Balochistan under the China-Pakistan Economic Corridor. Journal of China Tourism Research, 1-19.

Hongdao, Q., Bibi, S., Khan, A., Ardito, L., \& Khaskheli, M. B. (2019). Legal Technologies in Action: The Future of the Legal Market in Light of Disruptive Innovations. Sustainability, 11(4), 1015

Haq, R., \& Farooq, N. (2016). Impact of CPEC on social welfare in Pakistan: A district level analysis. The Pakistan Development Review, 597-618.

Hussain, M., \& Jamali, A. B. (2019). Geo-political dynamics of the China-Pakistan economic corridor: a new great game in South Asia. Chinese Political Science Review, 4(3), 303-326.

Hanafi, H. (2018). Gastronomy, tourism, and the soft power of Malaysia. SAGE Open, 8(4).Hilali, A. (2020). China-Pakistan Economic Corridor (CPEC): A MultiDimensional Plan 2017-2030 and Its Characteristics. South Asian Studies, 34(2).

Kabiru, A. (2019). Impacts of Chinese Influence in Contemporary East Africa. China and East Africa: Ancient Ties, Contemporary Flows, 187.

Kaplan, B., \& Maxwell, J. A. (2005). Qualitative research methods for evaluating computer information systems. In Evaluating the organizational impact of healthcare information systems (pp. 30-55): Springer.

Khadaroo, J., \& Seetanah, B. (2007). Transport infrastructure and tourism development. Annals of tourism research, 34(4), 1021-1032.

Khan, A., Bibi, S., Ardito, L., Lyu, J., Hayat, H., \& Arif, A. M. (2020). Revisiting the Dynamics of Tourism, Economic Growth, and Environmental Pollutants in the Emerging EconomiesSustainable Tourism Policy Implications. Sustainability, 12(6), 2533.

Khan, A., Bibi, S., Lorenzo, A., Lyu, J., \& Babar, Z. U. (2020). Tourism and Development in Developing Economies: A Policy Implication Perspective. Sustainability, 12(4), 1618.

Khan, A., Bibi, S., Lyu, J., Alam, M., Khan, M. M., \& Nurunnabi, M. (2020). The quest of tourism and overall well-being: the developing economy of Pakistan. PSU Research Review.

Khan, A., Bibi, S., Lyu, J., Garavelli, A. C., Pontrandolfo, P., \& Perez Sanchez, M. A. (2020). Uncovering Innovativeness in Spanish Tourism Firms: The Role of Transformational 
Leadership, OCB, Firm Size, and Age. Sustainability, 12.

doi:https://doi.org/10.3390/su12103989

Khan, A., Bibi, S., Lyu, J., Latif, A., \& Lorenzo, A. (2020). COVID-19 and Sectoral Employment Trends: Assessing resilience in the US Leisure and Hospitality Industry. Current Issues in Tourism. doi:https://doi.org/10.1080/13683500.2020.1850653

Khan, A., Bibi, S., Lyu, J., Raza, A., Hayat, H., \& Meo, M. S. (2020). Unraveling the Nexuses of Tourism, Terrorism, and Well-Being: Evidence from Pakistan. Journal of Hospitality \& Tourism Research, 1096348020917742.

Khan, S. A. (2013). Geo-economic imperatives of Gwadar Sea Port and Kashgar economic zone for Pakistan and China. IPRI Journal, 13(2), 87-100.

Khattak, A. K., \& Khalid, I. (2013). China's One Belt One Road Initiative: Towards Mutual Peace \& Development. Journal of Research Society of Pakistan, 54(1), 1-20.

Kazi A (2017) "CPEC: Impact on Central and South Asia". In: CPEC Conference, Strategic Vision Institute, Islamabad.

Kanwal, S., Pitafi, A. H., Malik, M. Y., Khan, N. A., \& Rashid, R. M. (2020). Local Pakistani Citizensâ $€^{\mathrm{TM}}$ Benefits and Attitudes Toward Chinaâ€"Pakistan Economic Corridor Projects. SAGE Open, 10(3).Khalil, Samina. "Research Notes CPEC: Mutually Beneficial Growth Opportunities For China And Pakistan." Pakistan Journal of Applied Economics 27, no. 1 (2017): 139-144.

Kayani, F., Ahmed, M., Shah, T., \& Kayani, U. (2013). China-Pakistan Economic Relations: Lessons for Pakistan. Pakistan Journal of Commerce and Social Sciences, 7(3), 454-462.

Nazneen, S., Xu, H., \& Din, N. U. (2019). Cross-border infrastructural development and residents' perceived tourism impacts: A case of China-Pakistan Economic Corridor. International Journal of Tourism Research, 21(3), 334-343.

Orakzai, O. (2021). CPEC NEWS 10 Benefits that CPEC Brings to Pakistan. from Obortunity

Pakistan, M. (2016). A handbook on Pakistan's coastal and marine resources. MFF Pakistan: Karachi, Pakistan.

Pernecky, T. (2010). The being of tourism. The Journal of Tourism Peace Research, 1(1), 1-15.

Picken, F. (2017). Beach tourism. The SAGE international encyclopedia of travel tourism Recreation Research, 135-136.

Rahman, M. K., \& Zailani, S. (2017). The effectiveness and outcomes of the Muslim-friendly medical tourism supply chain. Journal of Islamic Marketing.Ramay, S. A. (2016). China Pakistan economic corridor: A Chinese dream being materialized through Pakistan.

Rehman, A. U., Hakim, A., Khan, K., \& Khan, I. U. J. R. J. o. T. I. (2018). Role of CPEC in development of trade, transport and economy of Pakistan. 7(1), 77-92.

Schroeder, T. (1996). The relationship of residents' image of their state as a tourist destination and their support for tourism. Journal of Travel Research, 34(4), 71-73.

Tadesse, E., Muhua, W., \& Lei, D. (2020). SWOT Analysis of Pakistan Education System: Impact of China-Pakistan Economic Corridor. Middle Eastern Journal of Research in Education Social Sciences, 1(2), 218-232.

Ullah, Z., Khan, J., \& Haq, Z. U. (2018). Coastal Tourism \& CPEC: Opportunities and Challenges in Pakistan. Journal of Political Studies, 25(2), 261-272.

Zaheer, C. K. R. (2006). Development and Operations of the Port of Gwadar. International Federation of Shipmaster's Associations. 